\title{
Comparison of Mood among Male and Female Workers as a Function of Reproductive Stage
}

\section{COMPARACION DEL ÁNIMO ENTRE LOS TRABAJADORES HOMBRES Y MUJERES COMO UNA FUNCION DE LA ETAPA REPRODUCTIVA}

\author{
Huerta-Franco Maria-Raquel', Miguel Vargas-Luna², Elba-del-Rosario Huerta-Franco ${ }^{3}$, Corina Flores-Hernández1, \\ Ana-Lilia González-Yebra', Ismael Morales-Mata', Aminta Jiménez Velázquez ${ }^{4}$ \\ 1. Departamento de Ciencias Aplicadas al Trabajo, Universidad de Guanajuato. \\ 2. Departamento de Ingeniería Física, Universidad de Guanajuato. \\ 3. Clínicas Odontológicas, University of Guadalajara. \\ 4. Instituto de Seguridad para el Servicio Social de los trabajadores del Estado (ISSSTE), León, Guanajuato, México.
}

\section{RESUMEN}

El propósito de este estudio fue comparar la frecuencia de alteraciones del estado de ánimo de los trabajadores masculinos y femeninos maduros. También se intentó demostrar la relación de los síntomas con algunos aspectos psicológicos como la autoestima de los voluntarios (AE), la satisfacción marital (SM) y las actitudes hacia la sexualidad (AHS). En un diseño transversal, se determina la frecuencia de la depresión, la ansiedad, los síntomas no específicos de la depresión (SNED), MS, y los sentimientos de síndrome del nido vacío (SSNV) en 103 hombres y 129 mujeres de 40 a 64 años de edad. Depresión, los SNED y la ansiedad fueron evaluados según los criterios DSM-III-R calificados con la prueba de Bech-Rafaelsen Hamilton. La AE se evaluó con la prueba Coopersmith, AHS y SSNV con un cuestionario previamente validado y SM con la prueba de selección De Weiss. Las mujeres se dividieron en función de su último período menstrual en pre, peri y postmenopáusicas. Los resultados demostraron que el SSNV fue más frecuente en mujeres que en varones $(\mathrm{p}=0,03)$. Las mujeres perimenopáusicas tuvieron mayor frecuencia de depresión, ansiedad y SNED que los hombres y las mujeres pre y posmenopáusicas. La $\mathrm{AE}$ fue asociada positivamente con alteraciones del estado de ánimo en el trabajo masculino y femenino. En los hombres, la MS estuvo significativamente asociada con SSNV y con la depresión y los SNED en las mujeres perimenopáusicas. Llegamos a la conclusión de que las alteraciones del estado de ánimo son más frecuentes en las mujeres que en los hombres maduros. También hemos demostrado que en las mujeres maduras una pobre $\mathrm{AE}$ podría ser un factor de riesgo para el desarrollo de problemas del estado de ánimo. En ambos, hombres maduros y mujeres posmenopáusicas, la MS juega un papel importante en la aparición de SSNV.

(Huerta-Franco M, Vargas-Luna M, Huerta-Franco E, Flores-Hernández C, González-Yebra A, Morales-Mata I, Jiménez A, 2013. Comparison of Mood among Male and Female Workers as a Function of Reproductive Stage. Cienc Trab. Ene-Abr; 15 [46]: 12-17).

Palabras clave: ÁNIMO, TRABAJADORES Y TRABAJADORAS, ETAPA REPRODUCTIVA

Correspondencia / Correspondence:

Maria-Raquel Huerta-Franco

Departamento de Ciencias Aplicadas al Trabajo,

Universidad de Guanajuato

Aquiles Serdán 924, Colonia Obregón, León, Gto, México

Tel.: +52 4772674900 Ext 4675

e-mail: mrhuertafranco@ugto.mx

Recibido: 09 de Marzo de 2013 / Aceptado: 28 de Marzo de 2013

\section{ABSTRACT}

The purpose of this study was to compare the frequencies of mood alterations of mature male and female workers. Also we aimed to demonstrate the relationship of symptoms with some psychological aspects such as volunteer's self-esteem (SE), marital satisfaction (MS) and attitudes toward sexuality (ATS). In a cross-sectional design, we determine the frequencies of depression, anxiety, non-specific symptoms of depression (NSSD), MS, and the feelings of empty nest syndrome (FENS) in 103 males and 129 females from 40 to 64 years of age. Depression, NSSD and anxiety were evaluated according to DSMIII-R criteria and scored with the Hamilton Bech-Rafaelsen test. SE was evaluated with the Coopersmith test, ATS and FENS with a previously validated questionnaire, and MS with the Pick De Weiss test. Women were divided according to their last menstrual period in pre- peri- and postmenopausal. The results demonstrated that FENS were more frequent in females than in males $(p=0.03)$. Perimenopausal women had higher frequencies of depression, anxiety, and NSSD than males and pre- and postmenopausal females did. SE was positively associated with mood alterations in both male and female labors. In males, MS was significant associated with FENS; and with depression and NSSD in perimenopausal females. We concluded that mood alterations are more frequent in mature females than in males. Also we demonstrated that in mature females poor SE could be a risk factor to development mood problems. In both mature male and postmenopausal females, MS plays an important role in the appearance of FENS.

Key words: MOOD, MALE AND FEMALE WORKERS, REPRODUCTIVE STAGE

\section{INTRODUCTION}

A high proportion of females workers demanding health care services suffer both physical and mood alterations, they attributed to the reproductive stage changes such as pre- or perimenopausal stages. ${ }^{1}$ However, a comparison of the mood alterations of preand perimenopausal workers, with that of middle aged men has not been sufficiently studied. In females workers mood alterations 
have been associated with multiple and diverse factors such as family functioning ${ }^{2,3}, \mathrm{MS}^{2}, \mathrm{ATS}^{4}$, hormonal and metabolic conditions $^{5}$, marital problems such as divorce, widowhood, and other life situations. ${ }^{4-6}$ Several of these factors could also be relevant for mood alterations of mature males. With age, males and females are more prone to present mood disturbances. In females, one of the peaks incidences of depression has been reported to occur at the early forties. ${ }^{7-10}$ Anxiety and depression symptoms are common, and may affect sexual performance. Awareness about the age-related changes in physical appearance indicates a poor self-image of sexual desirability. ${ }^{11}$ The increased frequency of physical and emotional symptoms in females at perimenopausal period has been well documented. ${ }^{10}$ Nonetheless for a better understanding of these problems, the frequency and severity of the female workers' mood alterations should be compared with those of similar age males. The concept of male climacteric is under dispute. ${ }^{12,13}$ Testicular function, at variance with ovarian function does not show and abrupt cessation. Mature male demonstrated a progressive decline in endocrine and spermatogenesis function. Yet, several factors associated with the onset of symptoms at this stage of the lifecycle may be similar for mature males and females workers. Nevertheless, both mature male and female suffer important changes about their expectations in life. Their unfulfilled expectations may have an impact on the perception of their self-esteem, and this may be an additional factor for explaining the onset of symptoms at this critical age. In this study, we evaluated the mood alterations of a three groups of active labor females according to their reproductive stage and we compared them with those of similar age active labor males.

\section{METHODOLOGY}

\section{Sampling}

This study was approved by the Academic Committee of the Institute of Security for the Workers 'Social Service from the Guanajuato's State (ISSSTE) and for the Division of Health Sciences Campus León, from the University of Guanajuato, México. The principal researcher, three physicians, and two technicians inform the workers about the study. For comparison reasons, in this study we used the same methodology to the one in our previous studies. ${ }^{4,5}$ Written informed consent was obtained from all volunteers, and the study was conducted according to the guidelines outlined in the Declaration of Helsinki World Medical Organization, $1996 .^{14}$

A group of 232 workers (129 females and 103 males) from 40 to 64 years of age, were studied in a cross sectional design. The sample of volunteers was a random selected from an outpatient clinics belong to the ISSSTE in Leon, Guanajuato, Mexico. Workers belong to a medium socioeconomic level which was determined as in our previous study. ${ }^{15}$ Inclusion criteria considered only occupational active subjects, who had elementary or more schooling level, without psychiatric illnesses and with no hormonal medication. Volunteers were divided in four groups: 1) Males from 40 to 64 years of age $(n=103) ; 2)$ premenopausal females $(n=38) ; 3)$ perimenopausal females $(n=55)$; and postmenopausal females $(n=36)$.

\section{Procedure}

Workers were assessed in the offices of family physicians at the ISSSTE. The procedures of the study were explained to them.
Evaluations were made from 8:00 to 12:00 AM. All the volunteers answer a questionnaire which included the following eight sections:

a) General data: date of the interview, birth date (with these data we calculated the decimal age of the workers), number of years in school; socio-economic level, which was evaluated as in previous studies using the Bronfman procedure ${ }^{15}$, we asked questions related to the place of residence, parent's occupation, family income, parent's schooling level, housing characteristics, number of rooms and people living at home, and services with which account the home.

b) Gyneco-obstetric antecedents: age at menarche, menstrual cycle lenght, number of pregnancies, number of abortions, cesarean, and gynecological diseases, which were asking using similar clinical evaluation as in previous studies., ${ }^{4,5}$

c) Occupation: we asked questions related to the type of occupation, number of days and hours per day spent at work. With these data we classify the occupation of workers as follows: professionals $=8$, teachers $=7$, technicians $=6$, office workers $=$ 5 , small commerce workers $=4$, blue collar workers $=3$, housewives $=2$ and others $=1$ ).

d) Life-Style: it includes questions related to the alcohol intake, smoking habits, drug abuse, and practice of regular physical exercise (which was evaluated according to the recommendations of American College of Sports Medicine). ${ }^{16}$ When a subject practice one or more modalities of sports or exercise, and if she/ he had practiced regular exercise for three or more months; three or more sessions per week, and more than 20 minutes for session, we considered as regular practice of physical exercise.

e) Somatic and psychological symptoms: depression, was evaluated with the Hamilton Scale. ${ }^{4,5}$ The non-specific symptoms of depression (NSSD), were evaluated according to the Hamilton Scale, modified by Bech. ${ }^{4,5}$ Anxiety was rated summing up 16 symptoms obtained from the Diagnostic and Statistical Manual of Mental Disorders. ${ }^{17}$ The empty nest syndrome (ENS), was evaluated as in previous works. ${ }^{18}$ Attitudes toward sexuality (ATS) see our previous works., ${ }^{4,5}$ Self-Esteem (SE), was assessed with the Coppersmith Test ${ }^{19,20}$; and Marital Satisfaction (MS) which was evaluated with the Scale of Pick and Andrade. ${ }^{21}$

\section{Somatic and Psychological Symptoms Scores}

Depression was scored as: slight (from 1 to 10 points), moderate (from 11 to 20), and severe (from 21 to 30 points); NSSD: slight (1 and 2 points), moderate ( 3 and 4 points), and severe ( 5 and 6 points); Anxiety: slight (from 1 to 5 points), moderate (from 6 to 10), and severe (from 11 to 16 points); FENS: slight (four points), moderate (from 5 to 8) and severe (from 9 to 11 points); ATS: poor (from 13 to 22), regular (from 23 to 44), and good (from 45 to 66 points); Self-Esteem: poor (from 1 to 8), regular (from 9 to 16) and good (>17 points); and Marital Satisfaction was rated as follows: good (from 64 to 72), regular (from 40 to 63) and poor (from 24 to 39 points).

\section{Anthropometrical Evaluation}

A medical certificated in anthropometry measurements performed the anthropometrical evaluation. Body weight was measured to the nearest $0,1 \mathrm{~kg}$ (weight) and height was measured to the nearest millimeter using a Bame Aut. Mod DGN 5282. With those data we obtained the body mass index (BMI weight $[\mathrm{kg}] /$ height $\left[\mathrm{m}^{2}\right]$ ). 
Measurements of the waist, hip and abdomen were also taken with a tape (Calibres Argentinos), in order to determine waist/hip and abdomen/hip indexes. Waist circumference was measured in the area corresponding to the lower boundary of the abdomen, usually located at the midpoint between the costal margin and the iliac crest. Hip circumference, was measured the maximum contour of the hip at approximately the level of the pubic symphysis and catching and most prominent point of the buttocks. Umbilical perimeter was measured at the contour of the abdomen at the level of the umbilicus.

\section{Analysis of data}

Differences among groups were tested using ANOVA. The relationship between physical and emotional symptoms with the anthropometric and life-style variables was tested with a multiple stepwise forward regression procedure and $\mathrm{J}^{2}$ test for categorical variables. Analyses of MS, was done only in individuals with partner. A significant data was considered when $p$ was $<0,05$. Statistical analysis was performed with STATISTICA, Stat-Soft, Inc. Tulsa OK, versión 7.0.

\section{RESULTS}

\section{General characteristics of the subjects included in the study}

The mean age for male workers was 47 years, and 42,4 for pre-, 45,5 for peri- and 51,2 for postmenopausal female workers. The mean age for the total group of female workers was $46,2 \pm 0,4$ (mean \pm standard deviation) as similar from those of males $(47,0 \pm 0,5, t=1,25, p=0,21)$. Educational level was higher for male than for female workers. The number of children, and the socioeconomic level were similar in the four group of subjects.

Distribution in frequencies of the workers by occupation The distribution of 232 workers (129 females and 103 males) by type of occupation was as follows: teachers 39\% males, 20\% females; qualified employees 28\% males, 18\% females; professional activities 14\% males, 13\% females, non-qualified employees $9 \%$ in the groups, and small commerce workers 10\% males, 7\% females. Among females 33\% were housewives. Alcohol was used occasional for 58\% males and $44 \%$ females, frequent but at a moderate level 9\% males and 1,6\% females; 44\% of males and $28 \%$ females were tobacco smokers. Thirty-eight per cent males and $24 \%$ females exercised physically on regular bases.

\section{Anthropometric variables and gynecologic antecedents}

The result of the anthropometric characteristics of the subjects evaluated indicates that peri- and postmenopausal females were mainly obese, with a BMI higher than $27 \mathrm{Kg} / \mathrm{m}^{2}$. Gynecologic and obstetric antecedents in the group of postmenopausal females indicates that 19 (59\%) were hysterectomies and 10 were also oophorectomies.

\section{Physical and emotional symptoms}

Postmenopausal female workers reported more frequently hot flushes (74\%) than pre- (36\%) and peri-menopausal women (60\%). Marginal differences were found between subgroups of males (those $<50$ years or $>50$ years of age) for depression, NSSD and ENS (higher scores for the group of younger males, $p=0,05$, $p=0,06$, and $p=0,06$ respectively), but not difference were demonstrated for anxiety $(\mathrm{p}=0,7)$, ATS, self-esteem, and MS. Those scores were similar between both groups of males $(p=0,28$ and $p=0,39)$. MS was marginally higher for older group of males $(p=0,09)$.

In table 1 , we demonstrated that peri-menopausal female workers had higher score of moderate depression and anxiety, although only anxiety was significantly different $(p=0,11$ and $p=0,009)$. Females workers had higher frequencies for moderate NSSD and ENS than male did ( $p=0,04$ and $p=0,03$ respectively). Scores of SE for both males and females were not significant different. All groups of females demonstrated higher frequencies of poor MS. The ANOVA test indicates that depression, anxiety, and NSSD were different between the groups $(p=0,009, p=0,0007$ and $p=0,001$ respectively. The less significant test (LST), demonstrated that males had less symptoms of depression and anxiety than females did. However, scores of psychological symptoms of pre-menopausal female workers, were not statistically different from those of males. The analysis of ENS and ATS, did not demonstrated significant differences $(p=0,38$ and $p=0,19)$ among the four groups of study. Table 1 also shows that the SE and MS scores were non-significant different among the four groups $(\mathrm{p}=0,81, \mathrm{p}=0,24$ and $\mathrm{p}=0,53)$.

\section{Factors associated with the symptoms of male and female workers}

In table 2, we present the results of the forward step-wise multiple regression analysis, demonstrated that in male workers, depression was negatively associated with self-esteem; the same tendency was demonstrated for pre- and postmenopausal females $(p<0,001$,

\section{Table 1.}

Frequency distribution of psychological symptoms of male and female workers. Number of cases (\%).

\begin{tabular}{|c|c|c|c|c|c|c|}
\hline & Male & Prem & Perim & Postm & $J_{1}^{2}$ & $P$ \\
\hline \multicolumn{7}{|l|}{ Depression } \\
\hline Slight & 73(70.9) & $28(73.7)$ & $36(65.5)$ & $23(63.9)$ & 5.9 & 0.11 \\
\hline Moderate & $13(12.6)$ & $7(18.4)$ & $17(30.9)$ & $8(22.2)$ & & \\
\hline Severe & ---- & ---- & --- & $1(2.8)$ & & \\
\hline \multicolumn{7}{|l|}{ Anxiety } \\
\hline Slight & $62(60.2)$ & $26(68.4)$ & $25(45.5)$ & $18(50.0)$ & 11.4 & 0.009 \\
\hline Moderate & $14(13.6)$ & $4(10.5)$ & $19(34.5)$ & $9(25.0)$ & & \\
\hline Severe & $3(2.9)$ & $3(7.9)$ & $3(5.5)$ & $3(8.3)$ & & \\
\hline \multicolumn{7}{|l|}{ NSSD } \\
\hline Slight & $62(60.2)$ & $24(63.2)$ & $35(63.6)$ & $20(55.5)$ & 8.4 & 0.04 \\
\hline Moderate & $6(5.7)$ & $7(18.4)$ & $14(25.5)$ & $8(22.2)$ & & \\
\hline Severe & $1(1.0)$ & --- & $1(1.8)$ & --- & & \\
\hline \multicolumn{7}{|l|}{ ENS } \\
\hline Slight & $82(79.6)$ & $20(52.6)$ & $37(67.3)$ & $22(61.1)$ & 8.9 & 0.03 \\
\hline Moderate & $10(9.7)$ & $8(21.1)$ & $10(18.2)$ & $8(22.2)$ & & \\
\hline Severe & --- & $1(2.6)$ & $1(1.8)$ & $1(2.8)$ & & \\
\hline \multicolumn{7}{|l|}{ ATS } \\
\hline Poor & ----- & ---- & $1(1.8)$ & ---- & 1.9 & 0.59 \\
\hline Moderate & $11(10.8)$ & $3(7.9)$ & $6(10.9)$ & $6(16.6)$ & & \\
\hline Good & $89(86.4)$ & $34(89.5)$ & $46(83.6)$ & 29(80.6) & & \\
\hline \multicolumn{7}{|l|}{ Self-Esteem } \\
\hline Poor & $4(3.9)$ & $1(2.6)$ & $4(7.3)$ & $2(5.6)$ & 1.9 & 0.57 \\
\hline Moderate & $19(18.5)$ & $6(15.8)$ & $12(21.8)$ & $10(27.7)$ & & \\
\hline Good & $77(74.7)$ & $31(81.6)$ & $39(70.9)$ & $29(66.7)$ & & \\
\hline \multicolumn{7}{|c|}{ Marital Satisfaction } \\
\hline Poor & $7(6.9)$ & $5(13.2)$ & $6(10.9)$ & $7(19.4)$ & 2.6 & 0.46 \\
\hline Moderate & $46(44.7)$ & $17(44.7)$ & $26(47.3)$ & $15(41.7)$ & & \\
\hline Good & $40(40.8)$ & $11(28.9)$ & $15(27.3)$ & $10(27.8)$ & & \\
\hline
\end{tabular}

Prem $=$ Premenopausal Females, Perim $=$ Perimenopausal Females, Postm $=$ Postmenopausal Females. NSS = Non-Specific Symptoms of Depression, ENS = Empty Nest Syndrome, ATS = Attitudes Toward Sexuality. $\mathrm{P}<0.05=$ Significant data. 
$\mathrm{p}<0,001$ and $\mathrm{p}<0,001$, respectively). In pre-menopausal female workers, depression was negatively associated with self-esteem $(\mathrm{p}<0,001)$ and with occupation $(\mathrm{p}=0,017)$. In male workers anxiety was positively associated with waist/hip ratio although significances disappear when "p" values were corrected with Bonferroni method. In peri-menopausal workers, anxiety was negatively associated with self-esteem ( $\mathrm{p}=0,024)$. NSSD were negatively associated with self-esteem in males $(p<0,001)$ and positively with waist/hip ratio $(p=0,019)$. In pre-menopausal female workers, NSSD were negatively associated with occupation, but significance was lost with Bonferroni correction. In both groups of females (peri- and post-menopausal), NSSD were negatively associated with MS. The ENS was negatively associated with self-esteem, MS and ATS. In post-menopausal females, those with occupation of higher hierarchy had less scores in empty nest syndrome $(p=0,009)$.

Table 2.

Factors associated with the male and female worker's psychological symptoms after a multiple stepwise regression analysis.

\begin{tabular}{|c|c|c|c|c|c|c|}
\hline & & $\beta$ & $\mathrm{t}$ & $P$ & $\mathrm{~N}$ & $\mathrm{Pc}^{*}$ \\
\hline \multicolumn{7}{|c|}{ Depression } \\
\hline \multirow[t]{2}{*}{ Male } & $\mathrm{R} 2=0.31 \mathrm{~F}(1,90)=40.5 p<0.001$ & & & & & \\
\hline & Self-Esteem & -0.56 & -6.3 & $<0.001$ & 100 & $<0.001$ \\
\hline \multirow[t]{3}{*}{ Prem } & $\mathrm{R} 2=0.57 \mathrm{~F}(2,29)=19.0 \mathrm{p}<0.001$ & & & & & \\
\hline & Self-Esteem & -0.61 & -4.8 & $<0.001$ & 38 & $<0.001$ \\
\hline & Occupation & -0.31 & -2.5 & 0.017 & 38 & 0.086 \\
\hline \multirow[t]{2}{*}{ Perim } & $R 2=0.32 F(1,44)=20.4 p<0.001$ & & & & & \\
\hline & Marital Satisfaction & -0.56 & -4.5 & $<0.001$ & 47 & $<0.001$ \\
\hline \multirow[t]{2}{*}{ Postm } & $\mathrm{R} 2=0.34 \mathrm{~F}(1,29)=14.9 p<0.001$ & & & & & \\
\hline & Self-Esteem & -0.58 & -3.9 & $<0.001$ & 36 & 0.003 \\
\hline \multicolumn{7}{|c|}{ Anxiety } \\
\hline \multirow[t]{3}{*}{ Male } & $\mathrm{R} 2=0.23 \mathrm{~F}(2,87)=13.2 \mathrm{p}<0.001$ & & & & & \\
\hline & Self-Esteem & -0.46 & -4.9 & $<0.001$ & 100 & $<0.001$ \\
\hline & Waist/Hip & 0.20 & 2.2 & 0.032 & 103 & 0.16 \\
\hline \multirow[t]{2}{*}{ Prem } & $\mathrm{R} 2=0.23 \mathrm{~F}(1,30)=8$ & & & & & \\
\hline & Self-E & -0.48 & -2.9 & 0.0057 & 38 & 0.03 \\
\hline \multirow[t]{2}{*}{ Perim } & $\mathrm{R} 2=0.17$ & & & & & \\
\hline & Self-Esteem & -0.41 & -2.9 & 0.004 & 55 & 0.02 \\
\hline \multicolumn{7}{|c|}{ Non Specific Symptoms Of Depression (NSSD) } \\
\hline \multirow[t]{3}{*}{ Male } & $\mathrm{R} 2=0.25 \mathrm{~F}(2,89)=14.5 \mathrm{p}<0.001$ & & & & & \\
\hline & Self-Esteem & -0.47 & -5.1 & $<0.001$ & 100 & $<0.001$ \\
\hline & Waist/Hip & 0.22 & 2.4 & 0.019 & 103 & 0.09 \\
\hline \multirow[t]{2}{*}{ Prem } & $R 2=0.12 F(1,30)=3.98 p<0.05$ & & & & & \\
\hline & Occupa & -0.34 & -1.9 & 0.054 & 38 & 0.32 \\
\hline \multirow[t]{2}{*}{ Perim } & $R 2=0.16 F(1,44)=8.6 p<0.005$ & & & & & \\
\hline & Marital Satisfaction & -0.40 & -2.9 & 0.053 & 47 & 0.032 \\
\hline \multirow[t]{3}{*}{ Postm } & $\mathrm{R} 2=0.36 \mathrm{~F}(2,28)=7.9 \mathrm{p}<0.001$ & & & & & \\
\hline & Self-E & -0.40 & -2.5 & 0.017 & 36 & 0.09 \\
\hline & Marital Satisfaction & -0.34 & -2.1 & 0.042 & 32 & 0.21 \\
\hline \multirow[t]{4}{*}{ Male } & $R 2=0.38 F(3,88)=18.3 p<0.001$ & & & & & \\
\hline & Self-E & -0.48 & -5.4 & $<0.001$ & 100 & 0.001 \\
\hline & faction & -0.23 & -2.6 & 0.012 & 95 & 0.04 \\
\hline & ATS & -0.18 & -2.2 & 0.031 & 100 & 0.12 \\
\hline \multicolumn{7}{|c|}{ Empty Nest Syndrome } \\
\hline \multirow[t]{3}{*}{ Prem } & $\mathrm{R} 2=0.30 \mathrm{~F}(1,29)$ & & & & & \\
\hline & Occupation & -0.36 & -2.2 & 0.033 & 38 & 0.17 \\
\hline & Self-Esteem & -0.33 & -2.1 & 0.047 & 38 & 0.24 \\
\hline \multirow[t]{2}{*}{ Perim } & $R 2=0.18 F(1,44)=9.5 p<0.004$ & & & & & \\
\hline & Self-Esteem & -0.42 & -3.1 & 0.003 & 55 & 0.02 \\
\hline \multirow[t]{3}{*}{ Postm } & $R 2=0.45 F(2,28)=11.4 p<0.001$ & & & & & \\
\hline & Marit & -0.73 & -4.7 & $<0.001$ & 32 & 0.001 \\
\hline & Occupation & -0.43 & -2.8 & 0.009 & 35 & 0.057 \\
\hline
\end{tabular}

NSSD $=$ Non-Specific Symptoms Of Depression, ENS = Empty Nest Syndrome, Prem $=$ Premenopausal Women, Perim $=$ Perimenopausal Women, Postm $=$ Postmenopausal Women. $\mathrm{Pc}^{*}=\mathrm{P}$ corrected with Bonferroni test.

\section{CONCLUSION}

In this study we investigated the factors associated with somatic and psychological symptoms of male and female workers from a population of medium socioeconomic level. As we reported in previous studies and according with data from other researchers, we demonstrated that frequency of hot flushes, depression, anxiety and NSSD, were greater in peri- and postmenopausal females than those observed in premenopausal females and male workers. ${ }^{4,5,7-9}$ Frequencies of the psychological symptoms found in this study were lower than those found in our previous report in postmenopausal females from a lower socioeconomic level. ${ }^{4}$ The influence of the reproductive transition on psychological symptoms is demonstrated by the finding of Avis et al. ${ }^{10}$, whose report that a long peri-menopausal period, lasting at least 27 months, was associated with increased risk of depression. ${ }^{21}$

The life cycle state of a worker is also important in the labor development; in this study we found that postmenopausal female workers had higher frequency of ENS in comparison with the other groups of workers. Even though, this result is similar to that of our previous report ${ }^{4,5}$, we demonstrated that females workers with high hierarchy in occupation had less scores in empty nest syndrome. One possible explanation of this finding is that at this stage, events that imply loses such as major illness of a family member, death or retirement of the spouse, uncertainty in employment, care to an elderly parents, children leaving home, and physical changes, have more impact in female workers with a less favored social and economic situation. ${ }^{18,22}$ Middle-aged females from low socioeconomic levels may be more prone to the effects of interpersonal stress caused by dominance and social abuse. We previously reported that low socioeconomic status and less education level had a negative association with psychological aspects in postmenopausal females.,5,23 Knowledge as a good information in topics related with psychological symptoms and work development in climacteric female workers is the best tool to avoid meets on taboo subjects. In accordance with our data, Dennerstein et $\mathrm{al}^{24}$, reported that 11 to 12 years of education is associated with a lowered risk of symptoms at menopause.

In the present study, we found that self-esteem was strongly associated, in a negative way, with the symptoms of mature female and male workers (depression, anxiety, NSSD and ENS). In accordance with this result, Philpot et al., also found significant correlations of self-esteem with depression in college students ${ }^{25}$, reinforce the hypothesis that male and female workers with low self-esteem will have less success in their occupational activities. Other researchers also reported that, physical symptoms and psychological state of well-being are mediated by the individuals' self-esteem. ${ }^{26}$ In the present study, self-esteem was found negatively associated with depression in postmenopausal female workers. Self-esteem, results from a complex interaction of factors, among which, vision of ones personal success and fulfillment of expectations are important factors. In this study we found that marital satisfaction was also associated with self-esteem of workers. It has been reported that persons with poor self-esteem may have feelings of apathy, loneliness and isolation. They may have less ability to love and are less reactive. In contrast, people with high self-seem have more dynamic life-styles, they have better control on adverse circumstances, less anxiety, better interpersonal relationship and they are more independent. ${ }^{19,20}$ For these reasons it is important to make an evaluation of the psychological health of the workers, in order to avoid a decrease in productivity. 
The results of step-wise multiple regression analysis demonstrated that in pre-menopausal female workers, occupation was negatively associated with depression, NSSD and ENS. These results mean that premenopausal female workers with high hierarchy in their occupation, have less depression, less non-specific symptoms of depression (changes in body weight, sexual interest, and alimentary habits), and less feelings of empty nest syndrome; results that are in agreement with those findings of other researchers. ${ }^{3}$ For this reason it is important, that female mature workers, have continual education in topics related with work performance of climacteric female and healthy lifestyle.

In relation to socio-cultural aspects, the gender and generational role of female Mexican workers, in the community they live in, is another important aspect related with mood and psychological symptoms, for example, in aspects such as familiar acceptance, practice of catholic religious and social conditions such as the civil status (lonely females, divorced or widowed) have impact in the mood of female workers. In this study, we found that marital satisfaction was another important aspect related with symptoms of workers; being more important for females than for males, because we could demonstrate that when marriages are unhappy, female workers have three-fold more risk of depression than male workers. $^{3}$ In support for the importance of this factor, AlonsoFernandez ${ }^{2}$, described that females with a satisfactory sexual life, have less problems at menopause. Attitudes toward sexuality are a factor related to marital satisfaction. In the present study, 80\% of the workers had high scores in ATS.

We previously demonstrated that in peri-menopausal females, ATS is associated with depression, anxiety, and ENS ${ }^{4}$; we also demonstrated that postmenopausal females with lower schooling level had significantly lower scores in ATS. ${ }^{5}$ The influence of schooling on ATS also was demonstrated in studies with adolescents and young adults. ${ }^{23}$ Some studies point out that the loss of sexual interest in postmenopausal females may be as high as $87 \% .^{9}$

In conclusion, peri- and postmenopausal female workers had higher scores in mood alterations than male did. Pre-menopausal female workers, with low hierarchy in occupation have high score of depression and self-esteem. However, post-menopausal females, with high hierarchy of occupation had fewer score in empty nest syndrome. Our findings are consistent with the concept that symptoms in mature female and male workers, result from an improper adaptation to the harsh environment of modern life at that critical period of the workers life. Self-esteem is an important indicator of several aspects of personal and social fulfillment. Decreased marital satisfaction and attitudes to sexuality facilitate a low familiar and conjugal adjustment. Low education and socioeconomic level make the mature workers, more liable to the stressful conditions of social dominance, and gives the workers a sense of an insecure future. The role of biological factors is not completely established in this respect, female workers have the additional influence of an abrupt change of hormonal conditions.

\section{ACKNOWLEDGEMENTS}

The authors thank all general practitioners and family physicians from the ISSSTE Leon, Guanajuato; especially to Dr. Aminta Jimenez Velazquez and all workers who agreed to participate in the study. 
1. Hammam Rehab AM, Abbas Reem A, Hunter Myra S. Menopause and work; The experience of middle-aged female teaching staff in an Egyptian Governmental Faculty of Medicine. Maturitas. 2012;71(3):294-300.

2. Alonso-Fernández F. Psicosis y psicomatosis de la vida genital femenina; Fundamentos de la Psiquiatría Actual. 4a ed. Madrid: Paz Montalvo; 1979.

3. Ulibarri MD, Semple SJ, Rao S, Strathdee SA, Fraga-Vallejo MA, Bucardo J, De la Torre A, Salázar-Reyna J, Orozovich P, Staines-Orozco HS, Amaro H, Magis-Rodriguez C, Patterson TL. History of abuse and psychological distress symptoms among female sex workers in two Mexico-U.S. border cities. Violence Vict. 2009;24(3):399-413.

4. Huerta R, Mena A, Malacara JM, Díaz de León J.Symptoms at perimenopausal period: its association with attitudes toward sexuality, life-style, family functioned FSH levels. Psychoneuroendocrinol.1995;20(2):135-148.

5. Huerta R, Mena A, Malacara JM, Díaz de León J. Symptoms at premenopausal and premenopausal years: Their relationship with insulin, glucose, cortisol, FSH, prolactin, obesity and attitudes towards sexuality. Psychoneuroendocrinol. 1995; 20(8):851-864.

6. Myers LS, Dixen J, Morrissette D, Carmichael M, Davison JM. Effects of estrogen, androgen, and progestin on sexual psychophysiology and behavior in postmenopausal women. J Clin Endocrinol Metab. 1990;70(4):1124-1131.

7. Chuni $\mathrm{N}$, Sreeramareddy CT. Frequency of symptoms, determinants of severe symptoms, validity of and cut-off score for Menopause Rating Scale (MRS) as a screening tool: a cross-sectional survey among midlife Nepalese women [en linea]. BMC Women's Health. 2011;11:30 [consultado mar 2013]. Disponible en: http://www.biomedcentral.com/1472.6874/11/30.

8. Huerta-Franco MR. El estado de ánimo de la mujer durante su ciclo reproductivo. Salud Mental. 2000;23(3):52-60.

9. Berlanga C, Huerta R. Los esteroides gonadales y la afectividad: el papel de las hormonas sexuales en la etiología y el tratamiento de los trastornos afectivos. Salud Mental. 2000;23(4):10-21

10. Avis NE, Brambilla D, McKinlay SM, Vass K. A longitudinal analysis of the association between menopause and depression: Results from the Massachusetts women's health study. Ann Epidemiol. 1994;4(3):214-220.

11. Master WH, Johnson VE, Kolodny RC. Human Sexuality. New York: Harper Collins College Publishers; 1992.

12. Cherrier MM, Asthana $S$, Plymate $S$, Baker L, Matsumoto AM, Peskind $E$,
Raskind MA, Brodkin K, Bremner W, Petrova A, LaTendresse S, Craft S. Testosterone supplementation improves spatial and verbal memory in healthy older men. Neurology. 2001;57(1):80-8.

13. Tsitouras PD, Martin CE, Harman SM. Relationship of serum testosterone to sexual activity in healthy elderly men. J Gerontol. 1982;37(3):288-93.

14. World Medical Organization. Declaration of Helsinki. BMJ. 1996;313 (7070);1448-1449.

15. Huerta R, Brizuela-Gamiño OL. Interaction of pubertal status, mood and self-esteem in adolescent girls. J Reprod Med. 2002;47(3):217-25.

16. Edward H. ACSM's Guidelines for Exercise Testing and Prescription. 6th ed. New York: Lippincott Williams \&t Wilkins; 2001.

17. American Psychiatric Association. Diagnostic and Statistical Manual of Mental Disorders. 4th ed. Barcelona: Masson; 2003

18. Malacara JM, Huerta R, Rivera, B, Esparza S, Fajardo ME. Menopause in normal and uncomplicated NIDDM women: physical and emotional symptoms and hormone profile. Maturitas. 1997;28(1):35-45.

19. Lara-Cantú MA, Verduzco MA, Acevedo M, Cortés J. Validez y confiabilidad del inventario de autoestima de Coppersmith para adultos, en población mexicana. Rev Latinoam Psicol. 1993;25(2):247-255.

20. Salgado de Sydney NV, Maldonado M. Respuestas de enfrentamiento e indicadores de salud mental en esposas de emigrantes a los Estados Unidos. Salud Mental. 1992;15(4):28-35.

21. Pick de Weiss S, Andrade P.Desarrollo y validación de la escala de satisfacción marital. Psiquiatria. 1988;4(1):9-20.

22. Dennerstein L, Atsbury J, Morse C. Psychosocial and mental health aspects of women's health. Geneve: World Health Organization; 1993.

23. Huerta-Franco R, Díaz de León J, Malacara JM. Knowledge and attitudes toward sexuality in adolescents and their association with the family and other factors. Adolescence. 1996;31(121):179-191.

24. Dennerstein L, Smith MA, Morse CA, Burger HG. Sexuality and the menopause. J Psychosom Obst Gynecol 1994;15(1):59-66.

25. Philpot VD, Holliman WB, Madonna SJr. Self-statements, locus of control, and depression in predicting self-esteem. Psychol Rep.1995;76(3Pt1):10071010.

26. Sweeting $H$, West $P$. Family life and health in adolescence: a role for culture in the health inequalities debate? Soc Sci Med. 1995;40(1):163-75 